\title{
Studies on the Promotion of Nickel-Alumina Coprecipitated Catalysts
}

\section{Titanium Oxide}

H.G.J. LANSINK ROTGERINK, P.D.L. MERCERA, J.G. VAN OMMEN and J.R.H. ROSS*

University of Twente, Faculty of Chemical Technology, P.O. Box 217, 7500 AE Enschede (The Netherlands)

(Received 5 April 1988, revised manuscript received 8 August 1988)

\section{ABSTRACT}

A series of $\mathrm{TiO}_{2}$-promoted nickel-alumina catalysts has been prepared and characterized. The promoter was added in various proportions to a calcined coprecipitated nickel-alumina material by adsorption of the acetylacetonate complex of titanium, followed by further calcination and reduction. The structure of the resultant materials was similar to that of the unpromoted coprecipitated nickel-alumina. The chemisorption properties of the catalyst and its behaviour in the $\mathrm{CO} / \mathrm{H}_{2}$ reaction were characteristic of a strong metal-support interaction (SMSI) reported in the literature for $\mathrm{Ni} / \mathrm{TiO}_{2}$. The strong adsorption of both carbon monoxide and hydrogen were suppressed while the activity for carbon monoxide hydrogenation was increased, the activation energy being lowered. The higher activity, however, was relatively unstable under reaction conditions.

\section{INTRODUCTION}

Much research on nickel-alumina coprecipitated catalysts has been carried out over the last few years [1-6]; part of this work has been reviewed [7]. The coprecipitated materials were shown to have rather small nickel-crystallites which are very resistant to sintering. These materials are therefore suitable for use in high-temperature hydrogenation reactions such as the methanation of $\mathrm{CO}+\mathrm{H}_{2}$ gas streams containing relatively large amounts of carbon monoxide. This reaction could become of industrial importance in due course for the production of methane or substitute natural gas (SNG). This was already the case some years ago, before large quantities of natural gas were discovered [7]. Since the reserves of natural gas are limited, it can be expected that the industrial importance of the methanation reaction will grow again in the future. This depends strongly on the situation in the oil- and gas-producing countries.

A subject which has received a lot of attention in catalysis research over the 
last decade is the interaction between group VIII metals and certain reducible oxides; this is known as strong metal-support interaction (SMSI). One of the most studied systems in this area is $\mathrm{Ni} / \mathrm{TiO}_{2}$. Tauster et al. [8] and Tauster and Fung [9] were the first to show that SMSI catalysts had a remarkably low chemisorption capacity for both carbon monoxide and hydrogen. Vannice and Garten $[10,11]$ demonstrated that this resulted in a dramatic increase in turnover number in the methanation reaction. They also reported activity data expressed per gram of nickel. In this case, the differences in the activities for $\mathrm{Ni} / \mathrm{TiO}_{2}$ and $\mathrm{Al}_{2} \mathrm{O}_{3}$ or $\mathrm{SiO}_{2}$-supported nickel catalysts are much smaller than in the case of turn-over numbers but the activities per gram of nickel for the $\mathrm{TiO}_{2}$-supported samples are higher than for the other samples [10]. In interpreting activity data given by other authors care must be taken since they sometimes report activity data which are based only on turn-over numbers. Since the turn-over numbers are either based on hydrogen chemisorption or carbon monoxide chemisorption, both of which can be greatly suppressed for this type of catalyst, these numbers give a somewhat too optimistic picture from an industrial point of view. For industrial applications it is, amongst other criteria, necessary that the activity per gram of catalyst or per volume of catalyst is high.

Using $\mathrm{TiO}_{2}$ as the catalyst support, however, has one disadvantage, namely the low resistance to sintering. This material is therefore not suitable for use in the methanation of gas streams which contain large amounts of carbon monoxide, since very high temperatures are reached as a result of the large exothermic heat of reaction. We asked ourselves if it was possible to combine the good thermal stability of the nickel-alumina coprecipitated catalysts with the higher activity of $\mathrm{Ni} / \mathrm{TiO}_{2}$. The strategy followed was to promote a coprecipitated and calcined nickel oxide-alumina material with $\mathrm{TiO}_{2}$. Upon reduction, the $\mathrm{TiO}_{2}$ would be converted to $\mathrm{TiO}_{x}$ and the catalyst would have the desired SMSI properties.

This approach has not often been used up to now. Yermakov et al. [12] promoted $\mathrm{Ni} / \mathrm{SiO}_{2}$ with $\mathrm{TiO}_{2}$ and found activities and selectivities intermediate between those of $\mathrm{Ni} / \mathrm{SiO}_{2}$ and $\mathrm{Ni} / \mathrm{TiO}_{2}, \mathrm{McVicker}$ and Ziemiak [13] found intermediate hydrogen chemisorption properties for both platinum and rhodium on $\mathrm{TiO}_{2}-\mathrm{Al}_{2} \mathrm{O}_{3}$ combinations (as compared to $\mathrm{M} / \mathrm{TiO}_{2}$ and $\mathrm{M} / \mathrm{Al}_{2} \mathrm{O}_{3}$ ) and Ko et al. [14] found the same for nickel on $\mathrm{Nb}_{2} \mathrm{O}_{5} / \mathrm{SiO}_{2}$. Rieck and Bell [15] promoted $\mathrm{Pd} / \mathrm{SiO}_{2}$ with $\mathrm{TiO}_{2}$; they found that the activity of the material for the methanation reaction was increased and that the apparent activation energy was lowered.

So many papers have been written on the $\mathrm{Ni} / \mathrm{TiO}_{2}$ system and on the SMSI effect in general that it is virtually impossible to give a short review; we shall therefore give only a short summary of some of the most relevant papers.

The model for SMSI now widely accepted is the decoration model $[16,17]$. In this, the cause of the observed SMSI effect is thought to be the presence of 
$\mathrm{TiO}_{x}(x<2)$ on the surface of the group VIII-metal. These $\mathrm{TiO}_{x}$ moieties are formed in a reducing atmosphere at temperatures above $400^{\circ} \mathrm{C}$ and arrive somehow on the metal surface. It is not clear how this process takes place; most authors have claimed that it occurs by migration or surface diffusion, but De Bokx et al. [18] recently suggested that it was due to the formation of a nickeltitanium-oxygen compound (possibly $\mathrm{Ni}^{\prime} \mathrm{IiO}_{3}$ ) which upon reduction gives $\mathrm{TiO}_{2}$. According to Sanchez and Gazquez [19], the metal diffuses into the support along paths which are formed by the removal of some of the oxygen from the support.

Some investigators have pointed out the reversible character of the reduction of $\mathrm{TiO}_{2}$ to $\mathrm{TiO}_{x}$. Re-oxidation might occur by reaction with the water which is formed together with methane in the methanation reaction [20,21]. Anderson and Burch described experiments in which an enhanced activity was found to occur on a sample of $\mathrm{Ni} / \mathrm{TiO}_{2}$ which was apparently not in the SMSI state. They suggested that the enhanced activity is caused by special sites at the nickel-titania interface [22-24].

We shall describe in this article some effects of promoting a coprecipitated nickel-alumina catalyst with $\mathrm{TiO}_{2}$. The promoter was added in various amounts to a calcined coprecipitated nickel-alumina material. Both the structure after reduction and the dispersion were studied with X-ray diffraction (XRD) and XRD-line broadening (XLB); the reduction process was followed by thermogravimetric analysis (TGA). The adsorption behaviour of carbon monoxide and hydrogen was followed using TGA and temperature-programmed desorption (TPD) respectively. The selectivity in the $\mathrm{CO}+\mathrm{H}_{2}$ reaction was determined using on-line gas chromatographic analysis (GC) and the initial activity and stability were measured using differential scanning calorimetry (DSC).

\section{EXPERIMENTAL}

\section{Catalyst preparation}

The preparation of the catalysts was carried out in several sequential steps:

(i) coprecipitation of the unpromoted nickel-alumina precursor;

(ii) calcination of the precursor;

(iii) addition of a titanium compound (see below) to the calcined precursor;

(iv) calcination of the promoted material;

(v) reduction followed by passivation.

The coprecipitation of the precursor (using the constant $\mathrm{pH}$ method) has been described in detail elsewhere [5]. The experimental variables (temperature, concentrations, etc.) were chosen as before [1] with the exception that the batch-size (ca. $30 \mathrm{~g}$ ) was circa three times as high and that the time-span of the steps in the synthesis (one hour for coprecipitation and one hour for ageing in the mother solution) were for both twice as long. The calcination of 
the precursor was carried out in a tubular furnace using a stream of nitrogen. The temperature was increased at a rate of $2{ }^{\circ} \mathrm{C} / \mathrm{min}$ to $450^{\circ} \mathrm{C}$, the time at the final temperature being $3 \mathrm{~h}$. The calcined samples were stored in air.

For the addition of titanium, a preparation method was used which has been developed in our laboratory for the preparation of (sub-) monolayer catalysts, e.g. $\mathrm{Fe}_{2} \mathrm{O}_{3} / \mathrm{TiO}_{2}$ or $\mathrm{V}_{2} \mathrm{O}_{5} / \mathrm{Al}_{2} \mathrm{O}_{3}$ and $\mathrm{V}_{2} \mathrm{O}_{5} / \mathrm{TiO}_{2}$ [25-27]. In this method, the acetylacetonate complex of the desired metal is dissolved in an organic solvent and added to the support. The acetylacetonate complex reacts with the hydroxyl groups of the support, leading to a (sub-)monolayer of adsorbed complex. The organic part of this complex can be removed by calcination in air at $450^{\circ} \mathrm{C}$.

In this case, a solution of $1.8 \mathrm{~g} \mathrm{TiO}\left(\mathrm{C}_{5} \mathrm{H}_{7} \mathrm{O}_{2}\right)_{2}$ (titanyl acetylacetonate) per $\mathrm{dm}^{3}$ toluene was added to the calcined precursor in a reflux apparatus. The temperature was increased to $95^{\circ} \mathrm{C}$ and was maintained at that value for several hours (up to $6 \mathrm{~h}$, depending on the amount of titanium). The samples were dried overnight at $110^{\circ} \mathrm{C}$ in air and calcined at $450^{\circ} \mathrm{C}$ for $3 \mathrm{~h}$ in a nitrogen stream containing $1 \%$ oxygen after an initial temperature increase at a rate of $10^{\circ} \mathrm{C} / \mathrm{min}$. Several samples with different amounts of titanium $(0-10 \mathrm{wt} .-\%)$ were prepared following this procedure; all of these were based on the same batch of calcined precursor.

Reduction was then carried out in the tubular furnace in a $50 \%$ hydrogen/ $50 \%$ nitrogen gas stream. The heating rate was $2^{\circ} \mathrm{C} / \mathrm{min}$; the final temperature of $600^{\circ} \mathrm{C}$ was maintained for $6 \mathrm{~h}$. Finally the reduced samples were passivated overnight at $20^{\circ} \mathrm{C}$ in a nitrogen stream containing $0.5 \%$ oxygen. The chemicals used were all pro-analysis quality; the gases were very pure $(99.999 \%)$ and were not purified further.

\section{Characterization}

Chemical analysis (X-ray fluorescence (XRF) and atomic absorption spectroscopy (AAS)) was used to determine the $\mathrm{Ni} / \mathrm{Al}$-ratio and the amount of sodium contained in the calcined precursor. The amount of titanium in the calcined promoted samples was measured by XRF.

The processes of calcination and reduction were followed by thermogravimetric analysis (DuPont system: 990 control unit, 951 TG-system), using the same gases as in the tubular furnace. The heating rate used was $20^{\circ} \mathrm{C} / \mathrm{min}$. The starting weight of the samples (ca. $5 \mathrm{mg}$ ) was kept as constant as possible since the DTG peaks tended to shift to higher temperature with increasing amounts of material. Another way to avoid the influence of the starting weight was to examine only the initial part of the peak.

The degree of reduction was also determined by TGA. Passivated samples (reduced in the tube furnace) were re-reduced at $420^{\circ} \mathrm{C}$ in order to remove the passivation layer and then re-oxidized to constant weight at $400^{\circ} \mathrm{C}$. The degree 
of reduction could be calculated from the weight increase and the sample composition.

\section{Phase analysis and particle size measurements}

Phase analysis of the materials was carried out using XRD (Philips PW1370, $\mathrm{Ni}$-filtered $\mathrm{Cu} K \alpha$ radiation). The unpromoted material was characterized both before and after calcination, and after reduction (as passivated material); the promoted samples were studied only after reduction and passivation.

Effective particle sizes (being equal to the cube root of the volume of the particles) were calculated from XRD line broadening (XLB) using the Scherrer equation $(K=1.0747)$ and the integral peak breadths of the $(200)$ and (111) reflections of nickel. The measured peak breadths were corrected for instrumental broadening. The broadening of the corrected peaks could then be used to calculate particle sizes. It is possible that lattice strain and/or paracrystallinity could also contribute to peak broadening. However, we have shown earlier [1] that, with the assumption made here, particle sizes are obtained which are reliable as long as they are used in a relative way.

In order to get real diameters, the effective diameter has to multiplied by the factor $(6 / \pi)^{0.333}$ or $(12 / \pi)^{0.3333}$ (assuming the crystals to be spheres or hemispheres respectively) [28]. Twice the thickness of the passivation layer has to be added to the computed value because this layer (on both sides of the particle) does not contribute to the measured XRD reflections of nickel; during the re-reduction process, the layer is transformed into nickel, thereby increasing the particle diameter. From the weight loss during re-reduction, the passivation layer was estimated for all our samples to be three monolayers thick. This value is in good agreement with the results of Coenen and Linsen [29] who found a value of two, of Dell et al. [30] who found a value of three, and of Montes et al. [31] who found a value of three to four monolayers.

\section{Adsorption measurements}

Gravimetric carbon monoxide adsorption was carried out in the TGA-apparatus. Passivated samples were re-reduced in hydrogen-nitrogen at $480^{\circ} \mathrm{C}$ and were subsequently cooled to $200^{\circ} \mathrm{C}$. After flushing with nitrogen, carbon monoxide ( $14 \%$ in nitrogen) was admitted and the weight increase was measured as a function of time.

Hydrogen adsorption measurements were performed in a TPD apparatus in which the hydrogen adsorbed irreversibly at $20^{\circ} \mathrm{C}$ was desorbed in an argon flow at temperatures up to $600^{\circ} \mathrm{C}$ and quantitatively detected by a thermal conductivity detector (TCD). Oxygen was removed from the argon carrier gas by a reduced coprecipitated nickel-alumina material which was contained in a separate reactor at a temperature of $400^{\circ} \mathrm{C}$. Water was removed by a molec- 
ular sieve (5A) trap. Details of the apparatus will be described elsewhere [32] in connection with hydrogen-TPD results obtained for several promoted nickelalumina catalysts.

\section{Activity measurements}

Activity measurements were carried out with a differential scanning calorimeter (DuPont 910 DSC) using a procedure described previously [33]. The samples (1-1.5 mg) were first re-reduced in a flow of hydrogen at $477^{\circ} \mathrm{C}$ and cooled to $150^{\circ} \mathrm{C}$. After admixing carbon monoxide $\left(\mathrm{H}_{2} / \mathrm{CO}=3.0\right)$, the temperature was increased to $400^{\circ} \mathrm{C}$ at a rate of $10^{\circ} \mathrm{C} / \mathrm{min}$. It was assumed that the only carbon containing product was methane (see the results given in the section on selectivity measurements). The rate of reaction was calculated from the rate of heat production measured by the $\mathrm{DSC}$ and the enthalpy of reaction $(-210 \mathrm{~kJ} / \mathrm{mol}$ carbon monoxide $)$. Plots of the natural logarithm of the reaction rate versus the reciprocal of the temperature gave a straight line whose slope is equal to $-E_{\mathrm{a}} / R, E_{\mathrm{a}}$ being the apparent energy of activation. The reproducibility of the activity at $300^{\circ} \mathrm{C}$ was within $8 \%$ and the apparent activation energy was within $2 \%$.

\section{Selectivity measurements}

Selectivity measurements were carried out in a fixed bed reactor with online gas analysis (Fig. 1).

The reactor consisted of a quartz tube (internal diameter $5 \mathrm{~mm}$ ) placed in a small oven. The catalyst particle sizes used were in the range of $0.3-0.6 \mathrm{~mm}$.

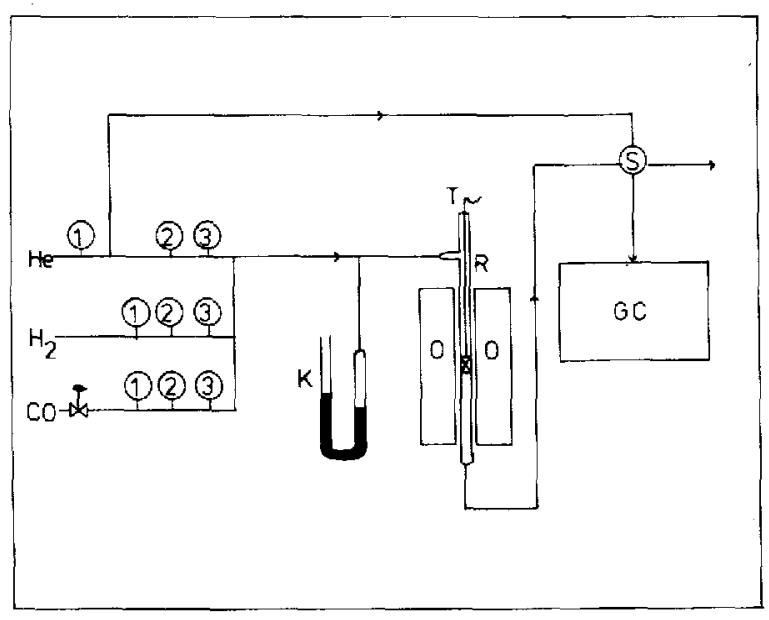

Fig. 1. Flow apparatus for selectivity measurements; $\mathrm{S}=$ sampling valve; $\mathrm{T}=$ thermocouple; $\mathrm{R}=$ reactor; $\mathrm{O}=$ oven; $\mathrm{K}=$ manometer; 1 =pressure regulator; $2=$ flow regulator; $3=$ flow indicator. 
A shielded thermocouple was placed on top of the catalyst bed, this consisting of $20 \mathrm{mg}$ of passivated material. The catalyst was first re-reduced in a helium stream containing $13.3 \%$ hydrogen (total $60 \mathrm{ml}(\mathrm{STP}) / \mathrm{min}$ ) at a temperature of $500^{\circ} \mathrm{C}$ (the heating rate to reach this temperature being $10^{\circ} \mathrm{C} / \mathrm{min}$ ). After cooling the sample to the reaction temperature (either $230^{\circ}$ or $300^{\circ} \mathrm{C}$ ), carbon monoxide was admixed $(2.6 \mathrm{ml}(\mathrm{STP}) / \mathrm{min})$, the hydrogen-to-carbon monoxide ratio being 3 . Gas analysis was performed with a Varian $3300 \mathrm{GC}$ (helium carrier gas and Carbosieve-S columns ). The carbon balance in the experiments carried out was in all cases within $5 \%$.

\section{RESULTS AND DISCUSSION}

\section{Unpromoted material}

The results of the characterization of the unpromoted material in its different stages of the preparation process were very similar to those found earlier for the material with identical composition [1]. They will therefore only be summarized here. The uncalcined precipitate consisted of a takovite compound $\left(\mathrm{Ni}_{6} \mathrm{Al}_{2}(\mathrm{OH})_{16} \mathrm{CO}_{3} \cdot 4 \mathrm{H}_{2} \mathrm{O}\right)$ and it had a higher degree of crystallinity than was observed previously. This was probably caused by the longer synthesis and ageing time used here. The increased crystallinity in the precursor stage had no influence on the nickel surface area after reduction and on the catalytic activity [2].

The sodium content was very low: $0.003 \mathrm{wt} . \%$; the $\mathrm{Ni} / \mathrm{Al}$-ratio was found to be $3.10 \pm 0.05$ ( 78.1 wt. $-\%$ nickel after reduction). After calcination, phase analysis (XRD) showed the presence of poorly crystalline NiO with lattice spacings which were somewhat lower than those found in pure $\mathrm{NiO}$. This was probably due to $\mathrm{Al}^{3+}$ ions dissolved or trapped in the $\mathrm{NiO}$ lattice [3,6,34]. If the measured line broadening of the $\mathrm{NiO}(220)$ peak (after correction for instrumental broadening) was ascribed fully to particle size effects, an effective diameter of $5.1 \mathrm{~nm}$ was found. No diffraction peaks of $\mathrm{Al}_{2} \mathrm{O}_{3}$ were present, the particles thus being either too small to be observed or amorphous.

After reduction, the effective particle sizes in the passivated sample were 5.2 and $5.3 \mathrm{~nm}$, as calculated from the $\mathrm{Ni}(111)$ and $\mathrm{Ni}(200)$ reflections respectively. As described in the Experimental section, the effective diameter is not identical to the real diameter (see Table 3, below). The degree of reduction was $98 \%$.

All these results were in very good agreement with those found and described earlier $[1,35]$.

\section{Promoted samples}

The amount of titanium brought onto the calcined precursor was varied by changing the amount of the solution of $\mathrm{TiO}(\mathrm{acac})_{2}$ in toluene and the reflux 
time. It was found that $80 \%$ of the dissolved titanium was adsorbed after $2 \mathrm{~h}$ of refluxing and almost $100 \%$ after $6 \mathrm{~h}$. The amounts of titanium adsorbed (measured by XRF) are given in Table 1 as the wt. $\%$ of titanium present after calcination.

The DTG curves of the reduction process for the promoted samples were the same as for the unpromoted sample: one broad reduction peak (peak temperature $535^{\circ} \mathrm{C}$ ) lying well above the reduction temperature of pure $\mathrm{NiO}$. There was no significant shift in the temperature as a function of the amount of titanium.

In a separate experiment, $\mathrm{TiO}_{2}$ was adsorbed on $\alpha-\mathrm{Al}_{2} \mathrm{O}_{3}$ by the acetyl-acetonate method. It was shown by TPR that the resultant $\mathrm{TiO}_{2}$, present at low concentrations, could be reduced to $\mathrm{TiO}_{1.5}$. This reduction was nearly complete at $600^{\circ} \mathrm{C}$.

The degree of reduction $(x)$ of the nickel oxide in the various samples is given in Table 2. These were calculated from the weight increase during the re-oxidation reaction either according to the equation:

$6.2[x \mathrm{Ni}+(1-x) \mathrm{NiO}] \cdot \mathrm{Al}_{2} \mathrm{O}_{3} \cdot y \mathrm{TiO}_{2} \rightarrow 6.2 \mathrm{NiO} \cdot \mathrm{Al}_{2} \mathrm{O}_{3} \cdot y \mathrm{TiO} \mathrm{O}_{2}$

or, making the extreme assumption that all of the $\mathrm{TiO}_{2}$ was reduced to $\mathrm{TiO}_{1.5}$,

\section{TABLE 1}

Weight percentage titanium in the calcined materials, and the molecular compositions $(y)$ based on $6.2 \mathrm{NiO} \cdot \mathrm{Al}_{2} \mathrm{O}_{3} \cdot y \mathrm{TiO}_{2}$

\begin{tabular}{lcl}
\hline Code & $\begin{array}{l}\text { Wt. } \% \\
\text { titanium }\end{array}$ & $y$ \\
\hline P-1-0 & 0.00 & 0.00 \\
P-1-0.5 & 0.43 & 0.05 \\
P-1-1 & 0.96 & 0.12 \\
P-1-2 & 2.01 & 0.25 \\
P-1-5 & 5.3 & 0.69 \\
P-1-10 & 10.9 & 1.57 \\
\hline
\end{tabular}

\section{TABLE 2}

Degree of reduction based on reactions (1) and (2)

\begin{tabular}{lcl}
\hline Code & \% red $(1)$ & \% red $(2)$ \\
\hline P-1-0 & $97 \pm 2$ & $97 \pm 2$ \\
P-1-0.5 & $98 \pm 2$ & $97 \pm 2$ \\
P-1-1 & $98 \pm 2$ & $97 \pm 2$ \\
P-1-2 & $97 \pm 2$ & $95 \pm 2$ \\
P-1-5 & $100 \pm 2$ & $95 \pm 2$ \\
P-1-10 & $102 \pm 2$ & $89 \pm 2$ \\
\hline
\end{tabular}


TABLE 3

Nickel particle sizes measured by XLB of the (111) and (200) reflections, assuming spheres or hemi-spheres

\begin{tabular}{|c|c|c|c|c|}
\hline \multirow[t]{3}{*}{ Code } & \multicolumn{4}{|c|}{ Nickel particle size (nm) } \\
\hline & \multicolumn{2}{|c|}{ Spheres } & \multicolumn{2}{|c|}{ Hemi-spheres } \\
\hline & $(111)$ & $(200)$ & (111) & $(200)$ \\
\hline$P-1-0$ & 8.0 & 8.2 & 9.8 & 10.0 \\
\hline P-1-0.5 & 8.0 & 8.9 & 9.8 & 10.8 \\
\hline P-1-1 & 8.4 & 8.7 & 10.3 & 10.7 \\
\hline P-1-2 & 8.9 & 8.9 & 10.8 & 10.8 \\
\hline P-1-5 & 9.1 & 9.1 & 11.2 & 11.2 \\
\hline P-1-10 & 9.0 & 8.3 & 11.0 & 10.2 \\
\hline
\end{tabular}

to the equation:

$6.2[x \mathrm{Ni}+(1-x) \mathrm{NiO}] \cdot \mathrm{Al}_{2} \mathrm{O}_{3} \cdot y \mathrm{TiO}_{1.5} \rightarrow 6.2 \mathrm{NiO} \cdot \mathrm{Al}_{2} \mathrm{O}_{3} \cdot y \mathrm{TiO}$

The possible errors given for the figures in Table 2 are caused mainly by the uncertainty in the Ni/Al-ratio $(3.10 \pm 0.05)$ and are such that we cannot discriminate between the two reactions. However, if we take into account the fact that $\mathrm{TiO}_{2}$ on $\alpha-\mathrm{Al}_{2} \mathrm{O}_{3}$ is reducible to $\mathrm{TiO}_{1.5}$ at the temperature used here (as was shown by TPR), it seems appropriate to assume that $\mathrm{TiO}_{2}$ in the promoted calcined samples is also reducible. It is impossible to distinguish between reduction to $\mathrm{Ti}_{2} \mathrm{O}_{3}, \mathrm{Ti}_{4} \mathrm{O}_{7}$, etc. because of the small amounts of $\mathrm{TiO}_{2}$ (relative to the amount of $\mathrm{NiO}$ ) and the relatively large errors involved.

The XRD diagrams of the reduced and passivated samples with up to 5.8 wt.-\% titanium showed no discernible peaks other than those of nickel. The sample P-1-10 however, contained $\mathrm{TiO}_{2}$ crystals which had the anatase structure. The real particle sizes of the nickel crystals, calculated according to the procedure given in the Experimental section, are given in Table 3.

The particle sizes are nearly constant for all samples. Since the degree of reduction was not strongly influenced by the amount of titanium, we would also expect the nickel surface areas to be almost equal for all the samples used.

\section{Carbon monoxide adsorption}

In this section, the results of gravimetric carbon monoxide adsorption on the titania-promoted nickel-alumina materials are described. The adsorption was initially very rapid (1-2 $\mathrm{min}$ ); however, a constant weight was not reached after $60 \mathrm{~min}$, although the rate of weight increase had become very small (Fig. 2 ). Both the rapid and total increases in weight (after $60 \mathrm{~min}$ ) are given in Table 4. 




Fig. 2. The amount of adsorbed carbon monoxide in mg per g nickel (measured by $\mathrm{TG}$ at $200^{\circ} \mathrm{C}$ ) as a function of time for sample P-1-0.5.

\section{TABLE 4}

Weight increases due to the adsorption of carbon monoxide on the titanium promoted samples (mg per $\mathrm{g}$ of nickel)

\begin{tabular}{llll}
\hline Code & $\begin{array}{l}\Delta W \text { (rapid) } \\
(\mathrm{mg} / \mathrm{gNi})\end{array}$ & $\begin{array}{l}\Delta W(\text { slow }) \\
(\mathrm{mg} / \mathrm{gNi})\end{array}$ & $\begin{array}{l}\Delta W \text { (total) } \\
(\mathrm{mg} / \mathrm{gNi})\end{array}$ \\
\hline P-1-0 & 22 & 15 & 37 \\
P-1-0.5 & 20 & 24 & 44 \\
P-1-1 & 14 & 32 & 46 \\
P-1-2 & 14 & 34 & 48 \\
P-1-5 & 16 & 28 & 44 \\
P-1-10 & 14 & 37 & 51 \\
\hline
\end{tabular}

As can be seen from Table 4, the presence of titanium influences both the slow and the rapid adsorption, the effect on the slow adsorption being most pronounced. The amount of carbon monoxide rapidly adsorbed decreases with increasing amount of titanium to $60-65 \%$ of the value found for the unpromoted material.

Gland et al. [36] performed experiments on the temperature-programmed desorption (TPD) of carbon monoxide as well as HREELS (High Resolution Electron Energy Loss Spectroscopy) experiments on clean and sulphur-modified $\mathrm{Ni}(100)$ surfaces. They concluded that carbon monoxide adsorbs linearly on a single nickel (atop site) up to a coverage of 0.5. Above this coverage, compressions takes place, further adsorption occurring at bridging sites. Carbon monoxide adsorbed on these sites desorbs at lower temperatures than does carbon monoxide adsorbed on the atop sites. From our own TPD-experiments, we know that the species which are initially adsorbed are the most strongly bound; this is in agreement with the results of Gland et al. From Table 4, it can be seen that $59 \%$ of the total amount is adsorbed rapidly and $41 \%$ is adsorbed slowly on the unpromoted $\mathrm{Ni} / \mathrm{Al}_{2} \mathrm{O}_{3}$. Although these figures are not completely 
in agreement with the $50 / 50$ values found by Gland et al., all the facts lead to the conclusion that the fast adsorption is taking place on the sites which adsorb carbon monoxide most strongly. Titania thus suppresses the strong adsorption and enhances the weaker adsorption.

Raupp and Dumesic [37] found similar results for titania-covered nickel and concluded that adsorbed titania species block carbon monoxide adsorption at strongly-bound sites (believed to be sites atop individual nickel atoms) and enhance adsorption at more weakly bound sites (believed to be hollow or bridging sites between nickel atoms). Fang et al. [38] performed carbon monoxide adsorption on $\mathrm{Ni} / \mathrm{TiO}_{2}$ and $\mathrm{Ni} / \mathrm{Ti}_{2} \mathrm{O}_{3}$, allowing 15 to $30 \mathrm{~min}$ to reach equilibrium. They came to the conclusion that the saturation-coverage did not vary much after reaching the SMSI state, but that the strength of adsorption had decreased.

Takatani and Chung $[39,40]$ exposed their samples of nickel supported on $\mathrm{TiO}_{2}$ foil to small doses of carbon monoxide and found decreasing adsorption of carbon monoxide with increasing coverage of titania; the amount levelled off at a constant value at a titanium coverage of 0.5 , the amount of carbon monoxide being one third of the initial amount. They explained the initial sharp decrease by assuming that one titanium deactivates nine nickel surface atoms for carbon monoxide adsorption. After prolonged reduction, which results in a high coverage of $\mathrm{TiO}_{x}$ on the nickel, only one carbon monoxide stretching band could be observed using HREELS. This band was attributed to carbon monoxide adsorbed on a site near the titanium oxide on the surface of the nickel. The observation that the amount of adsorbed carbon monoxide levelled off is in contrast to the results obtained by Zhao and Chung [41] for carbon monoxide adsorption on $\mathrm{MnO}_{x} / \mathrm{Ni}(111)$. In the latter case, carbon monoxide adsorption decreased continuously with increasing coverage of $\mathrm{MnO}_{x}$ even above the monolayer-level for $\mathrm{MnO}_{x}$.

Our results on titanium promoted nickel supported on alumina are in line with those mentioned above for the nickel-titania systems. The main conclusion is that $\mathrm{TiO}_{x}$ decreases the chemisorption capacity for strongly bound carbon monoxide and enhances the weaker adsorption.

\section{Hydrogen adsorption}

The hydrogen adsorption/desorption results will be discussed in detail elsewhere [32]. The results of Table 5 show the amount of adsorbed hydrogen which is adsorbed irreversibly at room temperature. This amount was measured by desorption experiments in the TPD apparatus, using a TCD detector.

It is clear that the amount of strongly adsorbed hydrogen decreases significantly with increasing amount of titanium. This type of behaviour is characteristic of materials in the SMSI state.

The amounts of strongly bound carbon monoxide and hydrogen as well as 


\section{TABLE 5}

Hydrogen irreversibly adsorbed at $25^{\circ} \mathrm{C}$ (arbitrary units/mg Ni)

\begin{tabular}{ll}
\hline Code & Ads. hydrogen \\
\hline P-1-0 & 16.6 \\
P-1-1 & 13.4 \\
P-1-5 & 6.9 \\
P-1-10 & 2.0 \\
\hline
\end{tabular}

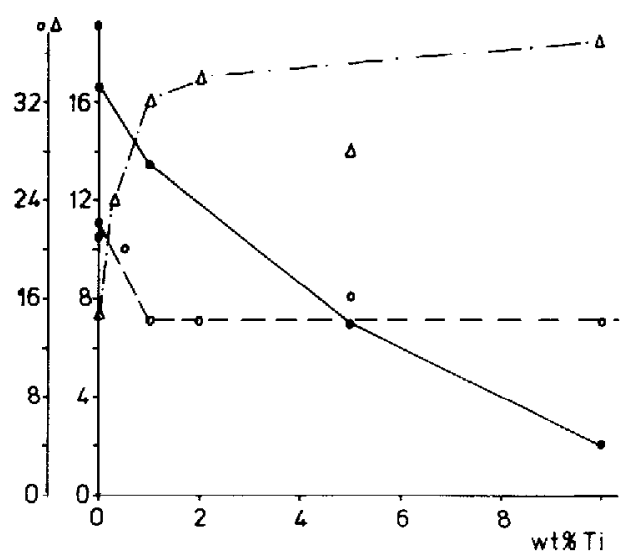

Fig. 3. Amounts (arbitrary units $/ \mathrm{mg}$ nickel) of carbon monoxide, both strongly (o) and weakly bound $(\Delta)$, and hydrogen $(\bullet)$ adsorbed as a function of wt.-\% titanium.

the amount of weakly bound carbon monoxide are plotted in Fig. 3 as a function of the percentage of titanium. Above $1 \mathrm{wt} . \%$ titanium hardly any change was observed in the amounts of both strongly and weakly bound carbon monoxide whereas the amount of strongly bound hydrogen decreases continuously. At low amounts of titanium (below $1 \mathrm{wt} . \%$ titanium), the adsorption of strongly bound carbon monoxide is decreased and the amount of weakly bound carbon monoxide is increased with increasing amount of the titanium.

\section{Selectivity measurements}

The selectivity measurements were performed at both 230 and $300^{\circ} \mathrm{C}$ on the samples P-1-0, P-1-1, P-1-5 and P-1-10. At these temperatures, only two carbon-containing products were observed: methane and carbon dioxide. At $300^{\circ} \mathrm{C}$, the conversion was ca. $60 \%$ and the selectivity towards methane was $86-91 \%$; at $230^{\circ} \mathrm{C}$, the conversion was ca. $20 \%$ and the selectivity towards methane was $90-96 \%$.

Some investigators (for example refs. 10-12) have reported increased selec- 
tivities towards higher hydrocarbons $\left(\mathrm{C}_{2+}\right)$ on $\mathrm{Ni} / \mathrm{TiO}_{2}$; however, these measurements were made exclusively at low conversions. Burch and Flambard $[22,23]$ reported $100 \%$ selectivity towards methane at the higher conversion of $40 \%$ in a $\mathrm{CO} / \mathrm{H}_{2}=1 / 3$ gas mixture, the selectivity towards higher hydrocarbons increasing with decreasing conversion. Kruissink [2] and Doesburg et al. [4] have shown that coprecipitated nickel-alumina catalysts produce higher hydrocarbons only when the $\mathrm{NiO}$ is reduced to a lower extent.

Our results are in accordance with these observations since we have done our measurements using highly reduced samples at high conversion levels.

\section{Activity and stability measurements}

The activity and stability measurements were performed in the DSC apparatus. Although, as shown in the previous section, the selectivity towards methane was lower than $100 \%$, the possible error in the figures for the activity [expressed as mol CO/(gNi $\cdot \mathrm{h})$ ] introduced by using DSC for the measurements, is at most $15 \%$; when the catalysts are compared with each other (relative activity), the error because of selectivity differences is less than $5 \%$. This section gives the activities measured at $300^{\circ} \mathrm{C}$, as well as the apparent activation energies; these were determined as described in the Experimental section. Arrhenius plots of the activity data obtained between 200 and $320^{\circ} \mathrm{C}$ gave straight lines for all samples except $\mathrm{P}-1-10$. The activities at $300^{\circ} \mathrm{C}$ (expressed as mol carbon monoxide per gram of nickel per hour) are plotted in Fig. 4 as a function of the weight percentage of titanium and the apparent activation energies are given in Fig. 5.

In order to examine the stability of the samples the activity was also followed as a function of time at 248 and $285^{\circ} \mathrm{C}$ (Fig. 6). Prior to the measurements the samples were re-reduced in hydrogen at $480^{\circ} \mathrm{C}$ and cooled to the reaction temperature. Carbon monoxide was admitted to the DSC cell at $t=0$; the $\mathrm{H}_{2} / \mathrm{CO}$ ratio had a value of 3.0. The heat production was followed as function of time for a period of ca. $100 \mathrm{~min}$.

All the samples, including the unpromoted material, were found to have a steady-state activity which was lower than the initial activity (see Fig. 6). The fact that the unpromoted sample loses some of its activity can be explained by the fact that it takes some time to reach a steady state. This will also be the case for the $\mathrm{TiO}_{2}$-promoted samples; however, these samples lose more of their initial activity and still remain somewhat more active than the unpromoted material at least over the first $100 \mathrm{~min}$. However, the activity of these samples decreases continuously, even after $100 \mathrm{~min}$. This indicates that the increased activity brought about by SMSI is only partly stable. This effect is more pronounced at 285 than at $248^{\circ} \mathrm{C}$.

Anderson et al. [21,24], Yermakov et al. [12] and Burch and Flambard [23] reported a similar behaviour of the activity as a function of time. They sug- 


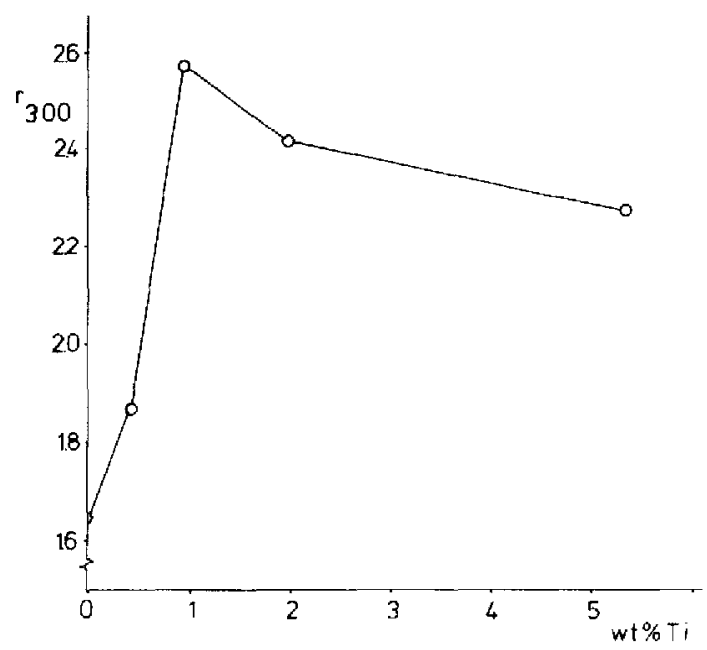

Fig. 4. Activity at $300^{\circ} \mathrm{C}[\mathrm{mol} \mathrm{CO} /(\mathrm{gNi} \cdot \mathrm{h})]$ as function of the weight percentage of titanium.

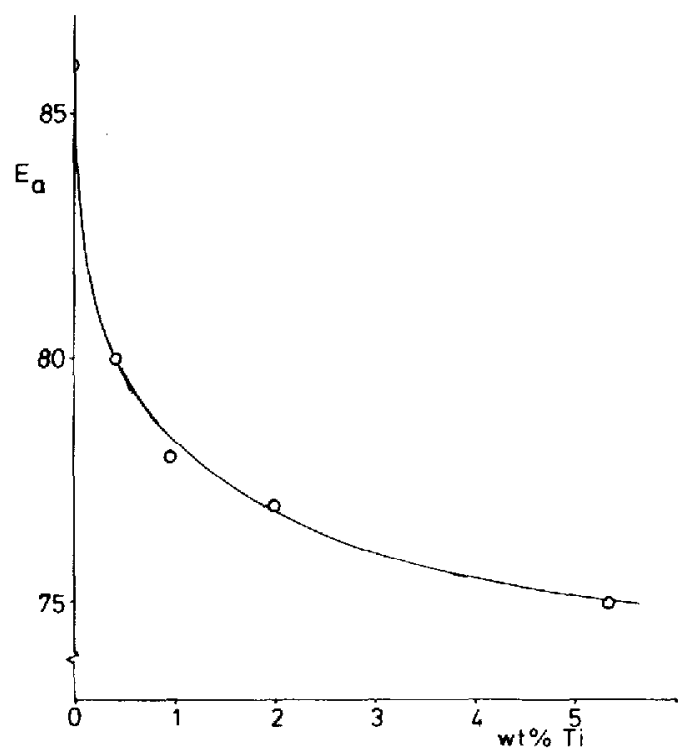

Fig. 5. Apparent activation energy $(\mathrm{kJ} / \mathrm{mol})$ as function of the weight percentage of titanium.

gested that the cause of this behaviour was probably the re-oxidation of the $\mathrm{TiO}_{x}$ by the water formed during the methanation reaction. This leads to the formation of $\mathrm{TiO}_{2}$ and hydrogen [21] and subsequently to the loss of SMSI properties. Raupp and Dumesic [42] performed adsorption/desorption experiments with several molecules on reduced $\mathrm{TiO}_{x}$. Their results indicate clearly that both carbon dioxide and water adsorb on reduced titania, oxidizing the surface, with desorption of carbon monoxide and hydrogen, respectively. 


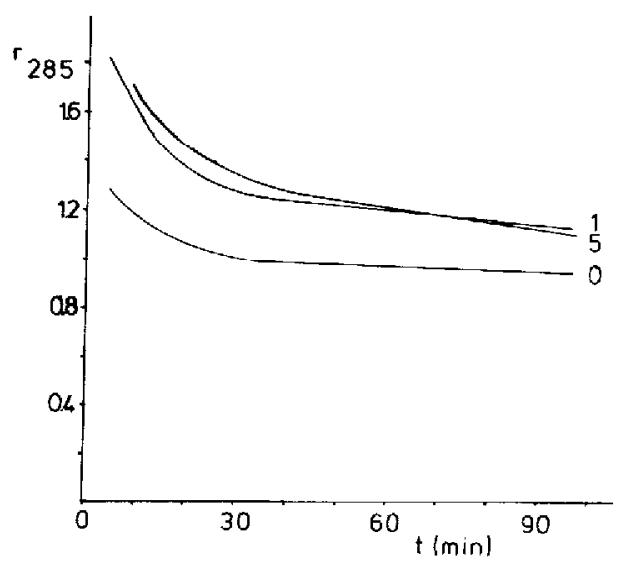

Fig. 6. Activity (mol carbon monoxide converted per g nickel per hour) versus time for samples P-1-0, P-1-1 and P-1-5; temperature of reaction: $285^{\circ} \mathrm{C}$.

As was shown above, the initial activity for the titanium promoted $\mathrm{Ni} / \mathrm{Al}_{2} \mathrm{O}_{3}$ catalysts was at its maximum (for sample P-1-1, see Fig. 4) a factor of 1.6 higher than for the unpromoted material. It is interesting to establish why this is the case. Raupp and Dumestic [43] have proposed a model in which the ratio between adsorbed hydrogen and carbon monoxide plays an important role. In "normal" (non-SMSI) nickel catalysts, the surface is nearly completely covered by carbon monoxide and/or carbon, leaving little room for hydrogen to adsorb. According to Raupp and Dumesic, SMSI catalysts have a larger activity because the heat of adsorption of carbon monoxide is lowered compared to the normal situation and the hydrogen is adsorbed more strongly. In this way, hydrogen can compete better with carbon monoxide for an adsorption site and the coverage of hydrogen on the catalyst surface is increased.

From our adsorption experiments, it is clear that the presence of titanium influences both the adsorption of hydrogen and of carbon monoxide. The changes in the adsorption of carbon monoxide occur exclusively at low amounts of titanium; above $1 \mathrm{wt}$. $\%$ titanium hardly any additional change was observed (Fig. 3). At low amounts of titanium, the amount of rapidly adsorbed carbon monoxide decreases whereas the amount of slowly adsorbed carbon monoxide increases. As was mentioned above, carbon monoxide which is adsorbed rapidly is believed to be strongly bound and carbon monoxide which is slowly adsorbed is believed to be weakly bound carbon monoxide (or less strongly held). So, the effect of titanium on the adsorption of carbon monoxide is that the overall strength of adsorption is lowered. In the model of Raupp and Dumestic this results in an increase in activity. As was shown in Fig. 4, this was actually measured. Above 1 wt. - \% titanium, the adsorption of carbon monoxide seems to be unchanged with increasing amount of titanium. However, in this range the amount of adsorbed hydrogen decreases strongly. According to 
the model given by Raupp and Dumesic [43], this has to result in a decrease in activity. As is shown in Fig. 4, this was indeed observed for our system.

Despite the fact that our hydrogen adsorption results are not completely in agreement with those of Raupp and Dumestic [43] (obtained with a titaniacovered nickel foil), their model explains in a satisfactory fashion the results obtained on our catalysts.

The change in apparent activation energy (Fig. 5) can also be explained as being a result of the changed heats of adsorption. In the model of Raupp and Dumestic, two temperature ranges are distinguished in which either carbon monoxide or carbon is the predominant species on the surface of the catalyst. At low temperatures, the most abundant species is adsorbed carbon monoxide and the activation energy is given by:

$E_{\text {app }}=E_{1}-\Delta H_{\mathrm{CO}, \text { ads }}$

In the upper temperature range, where carbon is the most abundant surface species, the apparent activation energy is given by:

$E_{\text {app }}=2 E_{2}+\Delta H_{\mathrm{H}, \mathrm{ads}}-E_{1}-\Delta H_{\mathrm{CO}, \mathrm{ads}}$

$-\Delta H_{\mathrm{CO}, \text { ads }}$ and $-\Delta H_{\mathrm{H}, \text { ads }}$ are the heats of adsorption for carbon monoxide and hydrogen respectively $(>0) . E_{1}$ and $E_{2}$ are the true activation energies for the dissociation of carbon monoxide and for the hydrogenation of carbon respectively. A decrease in the heat of adsorption of carbon monoxide leads to a decrease in the apparent activation energy for both temperature ranges. A decrease in the apparent activation energy in the high temperature range is found when the decrease in the heat of adsorption of carbon monoxide is larger than the decrease in that of hydrogen or, as Raupp and Dumestic have claimed, when hydrogen is adsorbed more strongly instead of more weakly.

\section{CONCLUSIONS}

Our characterization indicates that the structure of titanium promoted $\mathrm{Ni}$ / $\mathrm{Al}_{2} \mathrm{O}_{3}$ is identical to that of unpromoted $\mathrm{Ni} / \mathrm{Al}_{2} \mathrm{O}_{3}$; low amounts of $\mathrm{TiO}_{2}$ are present in dispersed form and the $\mathrm{TiO}_{2}$ can probably be reduced partially. After reduction at $600^{\circ} \mathrm{C}$, SMSI behaviour is observed. The chemisorption of both strongly bound carbon monoxide and hydrogen is suppressed but the adsorption of weakly bound carbon monoxide is enhanced. The initial activity of the reduced catalyst in the $\mathrm{CO} / \mathrm{H}_{2}$ reaction is increased and the apparent activation energy is decreased by the addition of titanium. This can be explained by a better competition between hydrogen and carbon monoxide for adsorption sites at the surface of the catalyst. The activity increase due to titanium is only partially stable. 


\section{ACKNOWLEDGEMENTS}

We should like to thank Hans Weber for performing some of the chemical analyses and Jaap Boeijsma for his help with X-ray measurements.

\section{REFERENCES}

1 H.G.J. Lansink Rotgerink, H. Bosch, J.G. van Ommen and J.R.H. Ross, Appl. Cutal., 27 (1986) 41.

2 E.C. Kruissink, Thesis, Delft University Press (1981),

3 E.B.M. Doesburg, P.H.M. de Korte, H. Schaper and L.L. van Reijen, Appl. Catal., 11 (1984) 155.

4 E.B.M. Doesburg, S. Orr, J.R.H. Ross and L.L. van Reijen, J. Chem. Soc., Chem. Comm., (1977) 734.

5 E.C. Kruissink, L.L. van Reijen, J.R.H. Ross, J. Chem. Soc., Faraday Trans. 1, 77 (1981) 649.

6 D.C. Puxley, I.J. Kitchener, C. Komodromos and N.D. Parkyns, in G. Poncelet, P. Grange and P.A. Jacobs (Eds.), Preparation of Catalysts III, Elsevier, Amsterdam, 1983, p. 237.

7 J.R.H. Ross, in G.C. Bond and G. Webb (Eds.), Catalysis, Vol. 7, Royal Society of Chemistry, Specialist Periodical Report, 1985, p. 1.

8 S.J. Tauster, S.C. Fung and R.L. Garten, J. Am. Chem. Soc., 100 (1978) 170.

9 S.J. Tauster and S.C. Fung, J. Catal,, 55 (1978) 29.

10 M.A. Vannice and R.L. Garten, J. Catal., 56 (1979) 236.

11 M.A. Vannice and R.L. Garten, J. Catal., 66 (1980) 242.

12 Y.I. Yermakov, Y.A. Ryndin, O.S. Alekseev and M.N. Vassileva, J. Chem. Soc., Chem. Commun., (1984) 1480.

13 G.B. McVicker and J.J. Ziemiak, J. Catal., 95 (1985) 473.

14 E.I. Ko, R. Bafrali, N.T. Nuhfer and N.J. Wagner, J. Catal., 95 (1985) 260.

15 J.S. Rieck and A.T. Bell, J. Catal, 99 (1986) 262.

16 J.A. Dumesic, S.A. Stevenson, R.D. Sherwood and R.T.K. Baker, J. Catal., 99 (1986) 79.

17 A.J. Simoens, R.T.K. Baker, D.J. Dwyer, C.R.F. Lund and R.J. Madon, J. Catal., 86 (1984) 359 .

18 P.K. de Bokx, R.L.C. Bonne and J.W. Geus, Appl. Catal., 30 (1987) 33.

19 M.G. Sanchez and J.L. Gazquez, J. Catal., 104 (1987) 120.

20 D. Dupres and A. Miloudi, in B. Imelik, C. Naccache, G. Coudurier, H. Praliaud, P. Meriaudeau, P. Gallezot, G.A. Martin and J.C. Vedrine (Eds.), Metal-suport and Metal-Additive Effects in Catalysis, Elsevier, Amsterdam, 1982, p. 179.

21 J.B.F. Anderson, R. Burch and J.A. Cairns, Appl. Catal., 21 (1986) 179.

22 R. Burch and A.R. Flambard, J. Catal., 78 (1982) 389.

23 R. Burch and A.R. Flambard, in B. Imelik, C. Naccache, G. Courudier, H. Praliaud, P. Meriaudeau, P. Gallezot, G.A. Martin and J.C. Verdrine (Eds.), Metal-Support and Metal-Additive Effects in Catalysis, Elsevier, Amsterdam, 19822, p. 193.

24 J.B.F. Anderson, J.D. Bracey, R. Burch and A.R. Flambard, Proc. 8th Int. Congr. Catalysis, Berlin, 1984, Verlag Chemie, Weinheim, 1984, Vol. 5, p. 117.

25 J.G. van Ommen, H. Bosch, P.J. Gellings and J.R.H. Ross, in B. Delmon, P. Grange, P.A. Jacobs and G. Poncelet (Eds.), Preparation of Catalysts IV, Elsevier, Amsterdam, 1987., p. 151.

26 J.G. van Ommen, K. Hoving, H. Bosch, A.J. van Hengstum and P.J. Gellings, Z. Phys. Chem. N.F., 134 (1983) 99. 
27 A.J. van Hengstum, J.G. van Ommen, H. Bosch and P.J. Gellings, Appl. Catal., 5 (1983) 207.

28 J.W.E. Coenen, Thesis, University of Delft (1958).

29 J.W.E. Coenen and B.G. Linsen, in B.G. Linsen, J.M.H. Fortuin, C. Okkerse and J.J. Steggerda (Eds.), Physical and Chemical Aspects of Adsorbents and Catalysis, Academic Press, London, 1970, p. 49.

30 R.M. Dell, D.F. Klemperer and F.S. Stone, J. Phys. Chem., 60 (1956) 1586.

31 M. Montes, Ch. Penneman de Bosscheyde, B.K. Hodnett, F. Delannay, P. Grange and B. Delmon, Appl. Catal., 12 (1984) 309.

32 H.G.J. Lansink Rotgerink, P.D.L. Mercera and J.R.H. Ross, in preparation.

33 T. Beecroft, A.W. Millar and J.R.H. Ross, J. Catal., 40 (1975) 281.

34 L.G. Simonova, V.A. Dzis'ko, M.S. Borisova, L.G. Karakchiev and I.P. Olen'kova, Kinet. Katal., 14 (1973) 1566.

35 H.G.J. Lansink Rotgerink, Thesis, 1988, University of Twente, Ch. 4.

36 J.L. Gland, R.J. Madix, R.W. McCabe and C. DeMaggio, Surf. Sci., 143 (1984) 46.

37 G.B. Raupp and J.A. Dumestic, J. Catal., 95 (1985) 587.

38 S.-M. Fang, J.M. White, T.J. Campione and J.G. Ekerdt, J. Catal., 96 (1985) 491.

39 S. Takatani and Y.-W. Chung, J. Catal., 90 (1984) 75.

40 S. Takatani and Y.W. Chung, Appl. Surf. Sci., 19 (1984) 341.

41 Y.-B. Zhao and Y.-W. Chung, J. Catal., 106 (1987) 369.

42 G.B. Raupp and J.A. Dumestic, J. Phys. Chem., 89 (1985) 5240.

43 G.B. Raupp and J.A. Dumestic, J. Catal., 96 (1985) 597. 